\title{
Effects of Magnetic Treatment on Leaching Releasing of Heavy Metals Element in Fly Ash from CFB
}

\author{
LIU Xin-Zhong, ${ }^{1,2,3}$ WENG Ren-Gui, ${ }^{1}$ XU Sheng, ${ }^{1}$ XIA Xue-Fen, ${ }^{1}$ WU Xiao-Hang, ${ }^{1}$ LIN Xiao-Ying ${ }^{1}$ \\ ${ }^{1}$ Fujian University of Technology, Fuzhou, Fujian 350007, P. R. China, \\ ${ }^{2}$ Shandong University of Technology, Zibo, Shandong 255049, P. R. China \\ ${ }^{3}$ Author for correspondence ( tel.:+86059188100989; fax:+86059188100989; e-mail: liuxinzhong@fjut.edu.cn)
}

\begin{abstract}
The effect of the intensity of magnetic field on the chemical activity and characteristics of heavy metals $\mathrm{Pb}$ and $\mathrm{Cr}$ in power plant fly ash from Circulating Fluidized Bed Boiler ( CFBFA) was studied through the project of Tessier's successive chemical extraction and successive leaching, according to the general regulation of the influence of magnetic treatment on water and minerals. The results show that the intensity of magnetic field has a distinct impact on the releasing amount of heavy metals in power fly ash. With the same leaching medium, the amount of releasing under the magnetic field with the intensity of $0.1 \mathrm{~T}$ is more than that with the intensity of $0 \mathrm{~T}$ and 0.25T. Meanwhile, the property and chemical activity of released heavy metals $\mathrm{Pb}$ and $\mathrm{Cr}$ are studied with the different $\mathrm{pH}$ value of leaching medium. The analysis of particles size distribution of power fly ash shows that the particles with smaller size are the majority of total particles, so the trace elements tend to enriching in smaller particles of power fly ash. The degree of enrichment of trace element is closely related to the average particle size of CFBFA.
\end{abstract}

Keywords : fly ash from CFB; leaching medium; successive leaching; heavy metal; magnetic treatment

\section{INTRODUCTION}

The main energy source in China is coal, which results in large quantities of fly ash from Circulating Fluidized Bed Boiler (CFBFA). Recently, China gains number-one world ranking for 160 million ton of fly ash produced by coal every year.. CFBFA is partially used in industry and agriculture, such as road building, cement making, concrete mixing, magnetized fertilizer mixing and so on. However, most of it is piled up but not in beneficial use. The fine particles $(<20 \mathrm{um})$ of the power fly ash are easy to enter the air, the water and the earth when people move and store the ash, which gives a bad effect on environment and zoology ${ }^{[2 \sim 3]}$.

Besides the elements of $\mathrm{Si}, \mathrm{Al}$ and $\mathrm{Ca}$, there are some trace elements in the power fly ash, including some noxious and radioactive heavy elements, such as $\mathrm{Cd}, \mathrm{Pb}, \mathrm{Cr}, \mathrm{As}, \mathrm{Zn}$, $\mathrm{Cu}$ and $\mathrm{Ni}$, which will cause the potential environmental pollution with increasing power fly ash production and stack, and it attracted close attention extensively by Environmental Chemists and Geochemists ${ }^{[3 \sim 5]}$.

The basic approaches to the disposal of fly ash are landfill and ash, while they both have their disadvantages ${ }^{[6 \sim 8]}$.

The power fly ash also has a bad effect on the terrestrial ecosystem due to leaching of potential toxic substances into soil and ground water which is not conducive to growth of the vegetation, changes components of the plants growing on it and increases the potential toxic substances which can be recycled and cumulated through food chains.

The significant impact on aquatic ecosystems can be described as follows: the polluting elements in the CFBFA can be soaked out continually by rains or leaching water into the surface and ground water; most items of the elute (such as $\mathrm{pH}$ value, rigidity, the content of oxide, sulfide, heavy metal, suspend substances etc) go beyond the Chinese standard of drinking water (GB5749-85) ${ }^{[8 \sim 14]}$ greatly.

Experiments of eluviation show that concentrations of heavy metals in the eluting out of power fly ash are 10 to 100 times as many as water quality standard (GH2B-1999 (IV、 $\mathrm{V})$ in China) ${ }^{[24 \sim 27]}$. it's reported that there are about billion tons of leaching water either running into surface water or used for agriculture in China every year.

Research is presented as follows: the chemical activity and its variational rules of heavy metals under magnetic field with different intensity; the impacts of magnetic field on leaching character of the heavy metals of fly ash under the natural condition.

\section{MATERIALS AND METHODS}

\subsection{Samples and analysis}

2.1.1 The composition of power fly ash

The experimental samples are provided by Baiyanghe

Electric Power Industry Company, Shandon, the major composition is listed in table 1 and the contents of trace elements in table 2 .

The main composes of the power fly ash are $\mathrm{SiO}_{2}$, $\mathrm{Fe}_{2} \mathrm{O}_{3}, \mathrm{Al}_{2} \mathrm{O}_{3}$ and $\mathrm{CaO}$, which make up $81.77 \%$ in total.

Table 1.Compositions of elements in the particles of power fly ash

\begin{tabular}{lccccccccccc}
\hline $\begin{array}{l}\text { Chemical } \\
\text { component }\end{array}$ & $\mathrm{SiO}_{2}$ & $\mathrm{Fe}_{2} \mathrm{O}_{3}$ & $\mathrm{Al}_{2} \mathrm{O}_{3}$ & $\mathrm{TiO}_{2}$ & $\mathrm{CaO}$ & $\mathrm{MgO}$ & $\mathrm{K}_{2} \mathrm{O}$ & $\mathrm{Na}_{2} \mathrm{O}$ & $\mathrm{SO}_{3}$ & $\mathrm{P}_{2} \mathrm{O}_{5}$ & Burning lost \\
\hline Content (\%) & 43.87 & 6.42 & 24.05 & 0.99 & 7.43 & 1.21 & 0.93 & 0.47 & 8.43 & 0.21 & 10.73 \\
\hline & & & & & & & & & & & \\
& Table & 2. Contents of trace elements in power fly ash & \\
\hline $\begin{array}{c}\text { Trace } \\
\text { Element }\end{array}$ & $\mathrm{Pb}$ & $\mathrm{Cr}$ & $\mathrm{Co}$ & $\mathrm{Ni}$ & $\mathrm{Cu}$ & $\mathrm{Zn}$ \\
\hline $\begin{array}{c}\text { Content } \\
\left(10^{-3} \mathrm{mg} / \mathrm{g}\right)\end{array}$ & 36.1 & 87.1 & 28.4 & 40.1 & 170 & 123 \\
\hline
\end{tabular}




\subsubsection{The phases in the power fly ash}

The X-ray examination shows that the fly ash in the experiment adopts main phase $\mathrm{SiO}_{2}$, hypo-phase $\mathrm{CaSO}_{4}$ and some $\mathrm{FeS}_{2}$.

\subsubsection{Granularity distributing character}

The grain sizes are listed in table 3 . It shows that the average size of the ash is $27.52 \mu \mathrm{m}, 93.27 \%$ ash particle within $80 \mu \mathrm{m}$ cumulation size, and $61.69 \%$ within $30 \mu \mathrm{m}$.

Table 3. Size distribution of power fly ash Time of ultrasonic treating: $120 \mathrm{~s}$

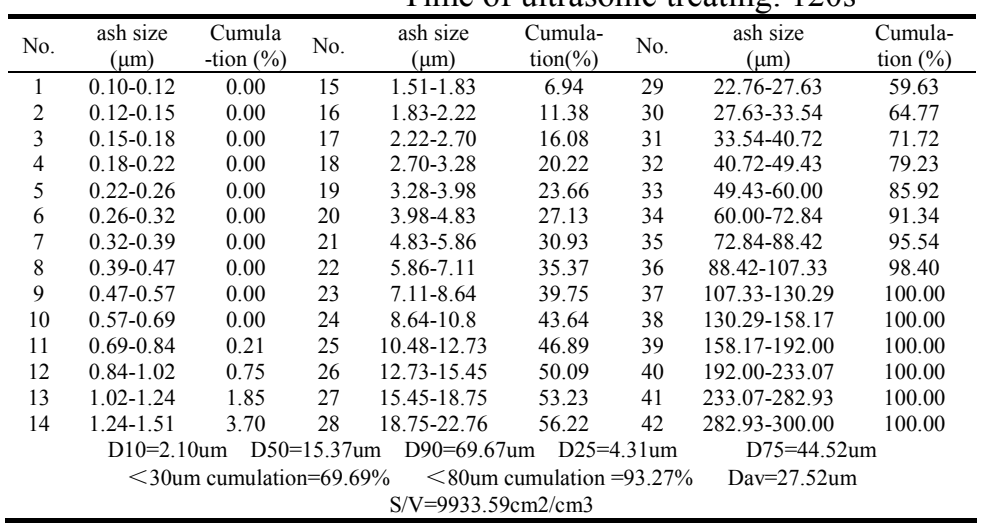

Disperse medium: distilled water

Concentration of sample: 1.4

Instrument: laser granularity analyzer (Winner2000)

\subsection{Selection of leaching medium}

The mixture of hydrochloric acid and nitric acid was selected by considering the acid rain and ash water treatment. The mixture acid solution was adjusted by diluted to a given $\mathrm{pH}$ value (at 6.00, 4.00, 2.00 respectively).

\subsection{The setting of leaching experiment}

The device of leaching experiment was shown as figure 1 .

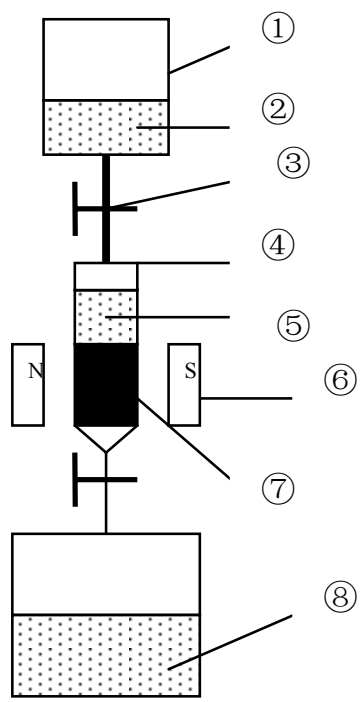

(1) Liquid container, (2) leaching liquid, (3) control valve, (4) leaching column,

(5) liquid film, (6) magnetic field, (7) fly ash, (8) the elute Figure 1.The sketch map of the leaching device

\subsection{Process of leaching experiment}

\subsubsection{The biacid impregnant preparative}

The biacid leaching medium made up of hydrochloric acid and nitric acid (3:1, volume ratio) is diluted to $1000 \mathrm{ml}$ with different $\mathrm{pH}$ value $(6.00,4.00$ and 2.00$)$ respectively, and kept in flasks.

\subsubsection{The leaching device}

Three sets of leaching device were assembled and each leaching device works under the four different magnetic fields with intensity $0 \mathrm{~T}(\mathrm{a}), 0.1 \mathrm{~T}$ (b), $0.25 \mathrm{~T}$ (c), $0.35 \mathrm{~T}$ (d) respectively.

\subsubsection{Power fly ash sample preparative}

The four leaching columns (sign a、 b、c and d) were loaded with $10 \mathrm{~g}$ power fly ash (weighed up by analytical balance) respectively.

\subsubsection{Experiment process}

The ratio of ash and biacid leaching medium is 1:20 (W/W) and $10 \mathrm{~g}$ power fly ash matches $200 \mathrm{~g}$ leaching medium. $10 \mathrm{~mL}$ leaching medium is added extrally in the first leaching process in order to make the elute around $200 \mathrm{~mL}$. The successive leaching method is adopted at the rate of 0.14 $\mathrm{mL} \cdot \mathrm{min}^{-1}$ and the leaching time is about $60 \mathrm{~h}$ in all.

At first, the $200 \mathrm{~mL}$ leaching medium with $\mathrm{pH}=6.00$ was introduced and the leaching time was $60 \mathrm{~h}$. Secondly, the elute was kept in a flask for analysis. Then the same amount of medium with $\mathrm{pH}=4.00$ was added. Finally, the same quantity of medium with $\mathrm{pH}=2.00$ was introduced. The processing of last two medium were similar to the process of the first one. All the experiments are carried out under $\mathrm{a}, \mathrm{b}, \mathrm{c}$ and $\mathrm{d}$ conditions respectively.

\section{RESULTS AND DISCUSSION}

\subsection{Results}

The contents of $\mathrm{Pb}$ and $\mathrm{Cr}$ elements in the leaching solution of power fly ash show in table 4, which were determined by ICP plasma emission spectrophotometry.

Table 4.The contents of $\mathrm{Pb}$ and $\mathrm{Cr}$ elements $(\mathrm{ng} / \mathrm{ml})$ in the leaching solution under different intensity of magnetic fields

\begin{tabular}{ccccccc}
\hline & \multicolumn{7}{c}{ Contents of $\mathrm{Pb}$ and Cr elements (ng/ml) } \\
$\begin{array}{c}\text { Intensity of } \\
\text { magnetic } \\
\text { fields (T) }\end{array}$ & \multicolumn{7}{c}{$\mathrm{pH}=6.00$} & $\mathrm{pH}=4.00$ & \multicolumn{2}{c}{$\mathrm{pH}=2.00$} \\
& $\mathrm{~Pb}$ & $\mathrm{Cr}$ & $\mathrm{Pb}$ & $\mathrm{Cr}$ & $\mathrm{Pb}$ & $\mathrm{Cr}$ \\
\hline 0 & 0.04 & 6.0 & $<0.02$ & 4.1 & $<0.02$ & 7.8 \\
0.10 & 0.39 & 5.2 & 1.4 & 6.5 & $<0.02$ & 8.4 \\
0.25 & $<0.02$ & 5.8 & $<0.02$ & 6.1 & $<0.02$ & 7.1 \\
0.35 & $<0.02$ & 5.5 & $<0.02$ & 5.8 & $<0.02$ & 6.5 \\
\hline
\end{tabular}




\subsection{Discussion}

\subsubsection{Leaching release properties of heavy metals under the different intensity of magnetic fields}

\subsubsection{Effect on $\mathrm{Pb}$ element leaching release under the different intensity of magnetic fields}

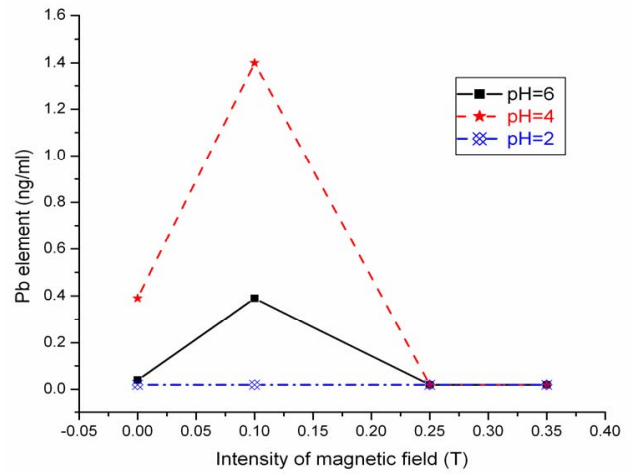

Figure 2.Leaching release of $\mathrm{Pb}$ under the different intensity of magnetic fields

As shown in Fig. 2, the content of $\mathrm{Pb}$ decreases with the increase of magnetic fields intensity by 60 hours leaching with $200 \mathrm{ml}$ leaching medium at $\mathrm{pH}=6.0$. At $\mathrm{H}=0$, the content of $\mathrm{Pb}$ is $0.04 \mathrm{ng} / \mathrm{ml}$, at $\mathrm{H}=0.1 \mathrm{~T}$, the content of $\mathrm{Pb}$ is ten times as many as it at $\mathrm{H}=0$, and at $\mathrm{H}=0.25 \mathrm{~T}$, the content of $\mathrm{Pb}$ is unexpectedly under $0.02 \mathrm{ng} / \mathrm{ml}$.

When the following leaching is at $\mathrm{pH}=4.0$, the $\mathrm{Pb}$ content of the elute varies with the increase of magnetic fields intensity at $\mathrm{H}=0.1 \mathrm{~T}$ and the leaching reaches the maximal $(1.4 \mathrm{ng} / \mathrm{ml})$. It can be conclused that the magnetic fields intensity takes important part in the leaching release of $\mathrm{Pb}$, and the maximal leaching release may be under magnetic fields intensity $0.1 \mathrm{~T}$.

When the last leaching underwent with $200 \mathrm{~mL}$ leaching medium at $\mathrm{pH}=2.0$, the $\mathrm{Pb}$ cannot be tested out, even at $\mathrm{H}=0.1 \mathrm{~T}$. Due to the successive leaching, the power fly ash has been undergone the leaching medium at $\mathrm{pH}=6.0$ and $\mathrm{pH}=4.0$ respectively, and the $\mathrm{Pb}$ content is rather few.

\subsubsection{The effect on $\mathrm{Cr}$ element leaching release under the} different intensity of magnetic fields

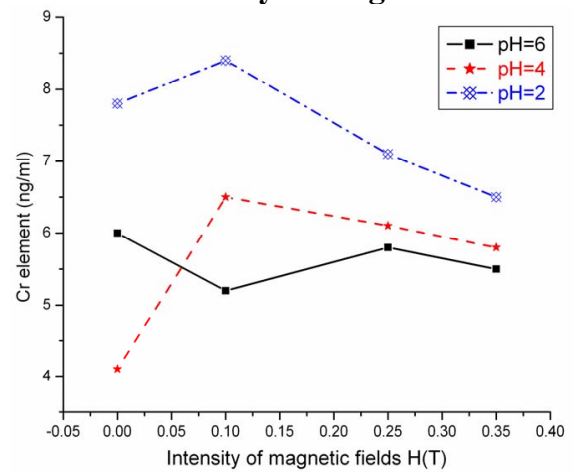

Figure 3.The leaching release of $\mathrm{Cr}$ under the different intensity of magnetic fields with different $\mathrm{pH}$ value
As shown in Fig 3, the intensity of magnetic field seems to put effect on the amount of $\mathrm{Cr}$ element leaching release slightly when leaching medium is adjusted to $\mathrm{pH}=6.0$, even at $\mathrm{H}(\mathrm{T})=0$, the leaching release is distinct. It means that the $\mathrm{Cr}$ element can cause pollution on the environment as long as the ash is washed by rain.

The ash was leached next by $200 \mathrm{~mL}$ leaching medium with $\mathrm{pH}=4.0$ (the red line in Fig 3). The experiment showed that the $\mathrm{Cr}$ concentration increased with the growth of intensity of magnet field at $\mathrm{H}<0.1 \mathrm{~T}$ and decreased with it at $\mathrm{H}>0.1 \mathrm{~T}$. The maximal concentration of $\mathrm{Cr}$ in elute was at $\mathrm{H}=$ $0.1 \mathrm{~T}$ and had a similar regular to the $\mathrm{Pb}$ leaching at $\mathrm{pH}=6.0$, that is, at $\mathrm{pH}=4$ and $\mathrm{H}=0.1 \mathrm{~T}$, the leaching concentration of $\mathrm{Cr}$ reached the maximal.

The blue line in fig. 3 show the concentration of $\mathrm{Cr}$ in elute at $\mathrm{pH}=2.0$, which also has a maximal concentration at $\mathrm{H}$ $=0.1 \mathrm{~T}$.

The $\mathrm{Cr}$ concentration of leaching filtrate is much larger than $\mathrm{Pb}$ concentration, and it can be attribute to the stronger combination state of $\mathrm{Pb}$ element in the ash.

\subsubsection{Leaching release properties of heavy metal elements in power fly ash in different $\mathrm{pH}$ value mediums}

3.2.2.1 The leaching release properties of $\mathrm{Pb}$ at different pH value

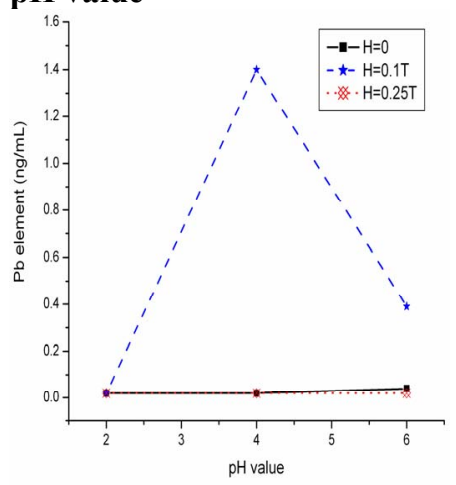

Figure 4. The leaching release concentration of $\mathrm{Pb}$ at different $\mathrm{pH}$ value

As shown in fig 4 , when the $\mathrm{H}=0$, the maximal concentration of $\mathrm{Pb}$ is at $\mathrm{pH}=6.0$ With the rising of the acidity, the release of $\mathrm{Pb}$ reduced. It is said that the $\mathrm{Pb}$ element can be lixiviated out at $\mathrm{pH}=6$ with no extra magnetic field. And it can conclused that the power fly ash will give a bad effect on the soil if it is piled up for a long time without any cover from rain in nature.

On the contrary, when the ash expose under strong magnetic field $(\mathrm{H}=0.25 \mathrm{~T})$, the release of $\mathrm{Pb}$ is limited, and can not be tested out.

At magnetic field $\mathrm{H}=0.1 \mathrm{~T}$, the release concentration varied great. The leaching medium with $\mathrm{pH}=4$ gave the maximal release concentration (the blue line in Fig. 3), at the same $\mathrm{pH}$ value, the $\mathrm{Pb}$ can not be tested out under $\mathrm{H}=0 \mathrm{~T}$ or $0.25 \mathrm{~T}$. As to leaching medium with $\mathrm{pH}=6$, the release concentration of $\mathrm{Pb}$ is about ten time as many as that under $\mathrm{H}=0 \mathrm{~T}$. 
The experiment reveals that the magnetic intensity plays an important part on the leaching process and on $\mathrm{Pb}$ leaching properties.

\subsubsection{The leaching release properties of $\mathrm{Cr}$ at different pH value}

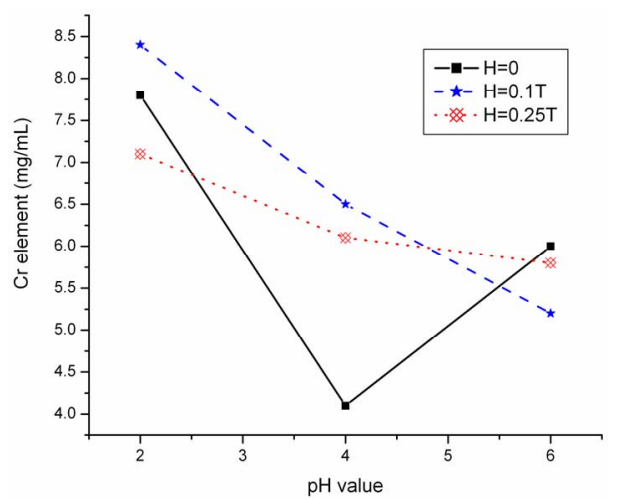

Figure 5.The leaching release concentration of $\mathrm{Cr}$ at different $\mathrm{pH}$ value

When $\mathrm{H}=0$, the leaching release concentration of $\mathrm{Cr}$ varied with the change of $\mathrm{pH}$ value. At $\mathrm{pH}=4$, the leaching release is much less than it at $\mathrm{pH}=2$ or 6 . At $\mathrm{pH}=2$, the concentration is the largest. At $\mathrm{H}=0.1 \mathrm{~T}$ and $0.25 \mathrm{~T}$, the concentration of $\mathrm{Cr}$ increased with the decrease of $\mathrm{pH}$, in other word, the leaching release increased with growth of the acidity. It can be concluded that $\mathrm{Cr}$ (III) solutes out of the ash increasedly while the acidity increases.

\subsubsection{Analysis on the total $\mathrm{Cr}$ and $\mathrm{Pb}$ of leaching release}

Table 5. The total $\mathrm{Pb}, \mathrm{Cr}$ in $200 \mathrm{ml}$ leaching filtrate

\begin{tabular}{lccc}
\hline $\begin{array}{l}\text { Magnetic } \\
\text { intensity }(\mathrm{T})\end{array}$ & 0 & 0.1 & 0.25 \\
\hline $\mathrm{Pb}\left(\times 10^{-2} \%\right)$ & 0.222 & 9.700 & 0.000 \\
$\mathrm{Cr}(\%)$ & 0.411 & 0.462 & 0.436 \\
\hline
\end{tabular}

Table 6. The leaching ratio of $\mathrm{Pb}$ and $\mathrm{Cr}$ out of power fly ash

\begin{tabular}{lccc}
\hline $\begin{array}{l}\text { Magnetic } \\
\text { intensity (T) }\end{array}$ & 0 & 0.1 & 0.25 \\
\hline $\mathrm{Pb}$ (ug) & 0.0080 & 0.0358 & 0.000 \\
$\mathrm{Cr} \quad$ (ug) & 3.58 & 4.02 & 3.80 \\
\hline
\end{tabular}

The tables show that there is no linear relationship between the leaching amount of $\mathrm{Cr}$ and $\mathrm{Pb}$ and the magnetic intensity. And it is showed that the maximal leaching locates within a range of magnetic intensity, or in a given intensity. Although the leaching amount varies greatly, the total leaching heavy elements is very few. The characteristic of leaching of heavy metals is effected by many factors such as medium solution, ratio of ash and leaching liquid, leaching time, leaching temperature, stir intensity etc.

\section{CONCLUSION}

4.1 The phases of the power fly ash from Circulation Fluidized Bed Boiler are mainly quartz, anhydrite and iron pyrites, whose main composings accounted for $81.77 \%$ are $\mathrm{SiO}_{2}$, $\mathrm{Fe}_{2} \mathrm{O}_{3}, \mathrm{Al}_{2} \mathrm{O}_{3}$, and $\mathrm{CaO}$.

4.2 The ash has a small mean granularity, only 27.52 um, and $56.22 \%$ of it around 22.72 um, only $30.93 \%$ less than 5.86 um.

4.3 The amount of $\mathrm{Pb}$ and $\mathrm{Cr}$ elements leaching is quite a few according to the analysis of the leaching ratio, and it will be less when leaching in the rain under the nature environment, so the heavy elements $(\mathrm{Pb}$ and $\mathrm{Cr})$ can not make obvious pollution to the soil.

4.4 The successive leaching experiments show that concentrations of $\mathrm{Cr}$ and $\mathrm{Pb}$ do not have the linear relation with the magnetic intensity. The control experiment shows that the maximal leaching release of $\mathrm{Pb}$ element occurs at $\mathrm{H}=0.1 \mathrm{~T}$ with medium $\mathrm{pH}=4.0$, and that of $\mathrm{Cr}$ element occurs at $\mathrm{H}=0.1 \mathrm{~T}$ with medium $\mathrm{pH}=2.0$.

\section{Acknowledgements}

This research Project is supported by the Natural Science Foundation of Fujian Province (Z0513016), the Natural Science Foundation of Shandong Province (Y2002E04), Fujian University of Technology (GY-Z0413) and scientific research foundation of the education department of Fujian province (JA05339)

Thanks also own to Researcher Xia Ning in Qingdao Institute of Marine Geology for the examination and testing for this work, and thank YaoDe of Shandong University of Technology for the help in this research work.

\section{References}

[1] Dong Feng-zhi, Yao De, Liu Xin-zhong. Influence of magnetic treatment on leaching and releasing characteristics of heavy metals in fly ash [J].Journal of Shandong University of Technology(Sci \& Tech), 2005, 19(6):4 8.

[2] Querol X,Juan R,Lopez-Soler A et al. Mobility of trace elements from coal and combustion wastes[J].Fuel,1996,(7):821.

[3] Fernandez-Turiel J L Carvalho de,Cabanas M et al. Mobility of heavy metals from coal fly ash[J].Environmental Geology,1994,23:264.

[4] Pavel Janos, Michaela Wildnerova. Leaching of metals from fly ashes in the presence of comlexing agents[J].Waste management,2002,22(7):783 789.

[5] Lu Xiao-hua, Ali A. Studies on the speciation distribution of heavy metals in particulates released from coal combustion[J]. Environmental chemistry, 1996,(4): 337 342.

[6] Zhang Qing-min, Hu Guo-chen, Wang Zhong. Study on Availability of Pb, Cd in Pulverous Coal Ash[J]. Agro-Environmental Protection, 2000, 350.

[7] Zhai Jian-ping. Analysis of impact of the harmful element contents change on soil and crop in farmland incurred by fly ash[J]. Electric power environmental protection,1997,(6):25.

[8] Jiao You. Characteristic and application of fly ash[]. Agro-Environmental \& Development,1998,(1):23.

[9] $\mathrm{Xu}$ Jia-quan. The rule of migration and transformation of injurious element chromium in water body environment[J]. Journal of china university of mining \& technology, 1994,(1): $53 \sim 58$

[10] Wang Y un-quan, Ren De-yi. Study on the Leaching Experiments of Minor and Trace Elements in coal and Its Bumt Products[J]. Chinese joumal of environmental science, 1997,17(1): 16 19.

[11] Matsukata M.,et al. Proceedings of Int.Conf. on Coal Science.Canada:Sep.1993:321 
[12] Zhao Feng-hua. Study on the Mechanism of Distributions and Occurrences of Hazardous Minor and Trace Elements in coal and Leaching Experiments of Coal Combustion Residues[D]. Journal of China University of Mining \& Technology(Beijing) 1997.

[13] Kooner Z S.Comparative study of adsorption behavior of copper,lead,and zinc onto goethite in aqueous system[J].Environ.Geol.,1993,21:242 250

[14] Ding Zhen-hua, Feng Jun-ming. Surface characters of iron-(hydro) oxides and their adsorption of heavymetal ions[]]. Acta Mineralogica Sinica, 2000,(4):349 351 .

[15] O'Day P A.Chisholm-Brause C J.Towle S N.et al.X-ray absorption spectroscopy of $\mathrm{Co}$ ( II ) sorption compexes on quartz $\left(\alpha-\mathrm{SiO}_{2}\right)$ and rutile $\left(\mathrm{TiO}_{2}\right)[\mathrm{J}]$.Geochim Cosmochim Acta.1996,60:2515 2532.
[16] Wu Da-qing, Peng Jin-lian, Diao Gui-yi. Kinetic study of the interface reactions between metal ions and sediment $\mathrm{CaCO}_{3}[\mathrm{~J}$. Geochimica, 2000,1:56 61 .

[17] Liu Xin-zhong, Yao De , Dong Feng-zhi. Research on disposal of acidic wastewater in the mine by flyash[]. Environmental Pollution \&Control, 2003.

[18] Wang Zhao-feng, Feng Yong-jun, Zhang Lei-na. Advances in studies in effects of fine coal ash on agricultural crops[J]. Shandong Agricultural University, 2003, 34(1): 152 156. 